\title{
Extrasensory Perception, Near-Death Experiences, and the Limits of Scientific Knowledge
}

\author{
Carl B. Becker, Ph.D. \\ Tsukuba University
}

\begin{abstract}
If mental state can influence the external world, or if alternate dimensions of reality are accessible only in certain mental states, then important aspects of the universe are unknowable with current scientific tools. Neardeath studies suggest that both those conditions may occur. Thus the exploration of NDE-like phenomena requires a radically new scientific paradigm.
\end{abstract}

Our common concern as philosophers and scientists is the question of the limits of scientific knowledge. In this paper, I shall argue that some significant aspects of the natural universe may be in principle unresolvable by the tools of natural science as presently practiced. To advance this claim, I propose two simple theses:

A. The mental state or conviction of the scientific investigator actually influences the behavior of the external world in some instances.

B. There exist other dimensions of the universe that are objectively real but accessible only to individuals in specific mental states.

If either of these theses proves defensible, then we must reconceptualize either the methods or the definitions of the sciences, or possibly

Dr. Becker is Assistant Professor of Philosophy at Tsukuba University. Requests for reprints should be addressed to Dr. Becker at the Institute of Philosophy, Tsukuba University, Tsukuba City 305, Japan. 
even concede that there exist insoluble scientific questions. In the following sections I shall treat each of these theses respectively.

\section{Influence of Observer Belief}

Since Werner Heisenberg's indeterminacy principle, it has become widely accepted that there are submolecular processes in the natural world that we cannot specify with precision, and that every investigation of these processes or particles inevitably influences them, so that their state while (and after) being investigated is different than it would be if they were left uninvestigated.

It is also widely known that scientists "find what they are looking for" (Kuhn, 1970, p. 135), and that they may unconsciously misreport or inaccurately observe data that fail to accord with their expectations (Bruner and Postman, 1958). Neither of these facts, however, constitutes a limit of science per se; they simply place limits on precision at one end of the microscopic scale, and suggest that we be very wary of self-fulfilling experiments.

There is another range of phenomena, however, that actually conform themselves to the convictions of the experimenter to a far greater degree than can be explained by individual differences or experimental error. The "sheep-goat" effect, in which "sheep" refers to believers and "goats" to hardened skeptics, holds that people who believe in and expect psychic abilities are far more likely to manifest them than are those who are skeptical of them. The "sheep-goat" effect has been found to hold true for a wide range of psychosomatic and paranormal phenomena, of which I shall consider a few examples here.

The sheep-goat effect was first documented in experiments in extrasensory perception (ESP), in which it was noted that some experimenters repeatedly failed to replicate standard ESP results, while others had no trouble in achieving results significantly indicative of ESP. It was concluded that the mindset of the experimenter was affecting the abilities of the subjects to perform. Numerous experiments have confirmed this sheep-goat effect in testing for clairvoyance (Schmeidler, 1963), ESP (Palmer, 1973), and out-of-body experiences (Palmer, 1975).

Another area to which the sheep-goat effect applies is that of psychosomatic interactions, especially placebo phenomena and the process of faith healing. Medical doctors have found that the mere expectation that a particular pill or injection would cure a particular ailment was sufficient to bring about healing, even when there were no active ingredients in the pill or injection, and when there were no medical reasons to expect healing of any kind. 
Similar situations may be observed in the cases of primitive medicine men and even in modern faith healing, where it is clearly not the specific dance or prayer that is curative, but rather the unwavering conviction of the patient that the particular treatment will cure him or her. Whether in Tenrikyo or in Christian Science, an absolute reliance on and commitment to the "principles" of the healer are required, and failure to be healed is attributed to inadequate faith (Becker, 1979). Sheep-goat effect research indicates that this is precisely what we should expect; it is not the content or practice of the belief that affects the healing as much as the firmness with which it is maintained.

Another simple illustration of the relationship between belief and the state of the world can be found in the use of invisible vital energy, called $c^{\prime} i$ in Chinese and $k i$ in Japanese, in the martial arts (Back and Kim, 1979). The martial arts practitioner who doubts his or her own vital energies will naturally be unable either to discover or to marshall them. Those who intuitively accept and work as if they have invisible energies will find themselves performing feats that the laws of physics and medicine would hold to be virtually impossible (Miller, 1980). Virtually every great master or practitioner of the martial arts insists upon the extreme importance of the cultivation of the appropriate frame of mind, even more than physical development, in order to perform the incredible feats for which martial masters have become known (Johnston, 1976).

In each of these areas-psychical research, psychosomatic healing, and martial arts - the connection between belief and objective reality is more profound than mere positive thinking. It suggests that the way the world, including human bodies, works is inextricably intertwined with the states of mind of the individuals in that world, including, of course, scientific investigators. If the sheep-goat effect is valid, it may indicate that there are areas in which humankind can never know the world objectively, not because of uncertainty principles and fudge factors, but because, in ways we do not understand, our minds actually change the physical universe. It remains to be seen whether this observer-belief factor influences other fields of scientific experimentation.

\section{Dimensions Accessible in Altered Mental States}

In the early part of this century, Ernst Mach speculated about the fourth spatial dimension as a purely mathematical construct that would also explain the sudden disappearance of objects in this world 
(Jacobson, 1974). Peter Ouspensky too did some rather wild philosophizing along this line, before Hornell Hart finally applied dimension theory to psychic phenomena (Hart, 1953). More recently, Herbert Benson worked out a version of fourth dimension theory that would make sense of both psychic phenomena and physical systems such as tunnel diodes (Benson, 1971). A growing number of physicists are becoming inclined to accept the possibilities of other dimensions, or hyperspaces, analogous to the dimensional system in which we live, but either inaccessible to or invisibly interpenetrating our own (Burt, 1967).

The possible existence of such inaccessible or interpenetrating but invisible dimensions has been used by philosophers and theologians to make sense of other worlds invisible to this one but real enough in their own right. John Hick and Alan Olding have seriously debated whether two spatially unrelated dimensions could be temporally related (Hick, 1976). Austin Farrer has suggested that "heaven can be as dimensional as it likes without ever getting pulled into our spatial field, or having any possible contact with us of any physical kind." (Farrer, 1965, p. 145). Even conservative Peter Geach granted the intelligibility of other spaces to make sense of Heaven and Hell (Geach, 1977).

The problem seems to be how humankind could know if there were different realms of reality inaccessible to each other. One solution lies in the suggestion that these dimensions may be experienced or even explored during certain unusual mental experiences of "privileged access."

Prima facie, the existence of other dimensions may appear analogous to the old philosophical bugaboo of the noumenon underlying phenomena; even if it exists, there seems to be no way of investigating or falsifying it, and therefore as a hypothesis about the world, it is useless and empty. However, in the case of fourth dimension theory, it is seriously suggested that there may be ways of accessing it.

Physicists have come up with some theories as to how black holes, antimatter, and subatomic entities may relate to other dimensions. Medical scientists have explored possible connections between extreme mental states and perceptions of other realms. I do not intend to argue that the nether worlds of heaven and hell could exist in the same dimensions as those to which antimatter and black holes flee. Rather, I shall focus on recent medical literature suggesting only one approach to dimension problems.

The past decade has seen a burgeoning interest in the subject of neardeath experience (NDEs). Many NDEs are easily explained away as 
hallucinations produced by chemical changes in the brain, therefore corresponding to no objective reality. When such cases have been discarded, however, what remains is a group of people making paranormal knowledge claims with unnervingly similar content. NDErs maintain that there is an objective reality to their experiences of relatives, friends, or religious figures in a realm of the departed.

In some cases, NDErs correctly identified persons as being dead whose death was yet unknown to anyone around them (Baird, 1944; Osis and Haraldsson, 1977). In other cases, people had visions of past or future events that could be proven to occur precisely as their NDEs had foreseen (Delacour, 1973). Many believe that this paranormal knowledge that transcends spatial and temporal barriers is possible because persons on the verge of death have begun to pass through a tunnel of mental energy into another dimension.

Kenneth Ring has argued that it is precisely to this other dimension that NDErs gain access in the transition from death to afterlife, a transition that increasing numbers of resuscitated people have described (Ring, 1980). Karl Pribram analogized the experience of mystics to those of another dimension, "bespeaking the possibility of tapping into that order of reality that is beyond the world of appearances" (Pribram, 1979, p. 84).

Charles Tart has seriously proposed that drug-induced altered states of consciousness could be utilized to gain access to and study the nature of such normally inaccessible dimensions. He propounded that our normal perceptual mechanism give us perspectives on only one particular dimension, and that modern science is specific to this state, but that theoretically, we might develop a whole range of "state-specific sciences," in which "explorers of other dimensions" might try to map coherent "landscapes" of other "dimensions," just as NDE accounts tend to be very consistent (Tart, 1972, pp. 1203-1210).

If there exist other dimensions that we can detect but explore only by inference or perhaps through near-death experiences, then this too would seem to constitute a limitation on natural science as presently understood. I do not intend to argue that humans do continue to live in other dimensions after death, nor even that there definitely exist such dimensions.

Rather, I am asserting that if such facts were to pertain, they might require revisions of thinking in scientific circles, and that there are both circumstantial evidence and philosophical thought to suggest that such facts might pertain within certain areas. In both near-death and mind-body research, we find fields in which objectivity must be reduced to something like comparisons of individuals' experiences. 
Some philosophers and scientists have tried to argue that the question of survival or life after death is a metaphysical one that cannot be formulated into a falsifiable and meaningful scientific hypothesis. But Hick (1977) has rigorously demonstrated that statements like "my consciousness will survive the death of my body" are both meaningful and falsifiable, although not necessarily by a community of observers all at once, and are important experiential questions about the content and nature of the universe, and not necessarily religious wand-waving nor gibberish.

The apparent anomalies of psychic and near-death phenomena discussed above leave us with several possible alternative explanations. The fact that "the existence of psi phenomena is clearcut scientific demonstration that our knowledge of the physical world is quite inadequate" (Tart, 1979, p. 182) will come as no surprise to philosophers of science, who for many other reasons have long agreed that science is still far from providing a complete understanding of the natural world.

The question for us today is rather whether such psychic and neardeath phenomena as we have alluded to will ultimately be explicable according to physical-like models and the methods of present science, or whether they shall always be impenetrable to interpretations by behaviorist and empirical models. This is currently a question of some debate in the literature on the subject (Pratt, 1979). Robert Binkley has aptly pointed out, "We are never entitled to declare that a certain effect must be non-physical just because it happens to be incompatible with any certain system of physics" (Binkley, 1966, p. 28).

\section{The Options of Interpretation}

There are several options open to philosophers of science and philosophical scientists at this point. They might construct an ad hoc, a priori definition that excludes the phenomena we have been considering from the purview of science. This has been the inclination of many traditional scientists, but it seems unjustifiably arbitrary, especially since the phenomena involved include perceptions, bodies, and medical states, traditional concerns of the natural sciences and philosophers of science. This world view "totally denies the existence of psi phenomena as we experimentally know them" (Tart, 1979, p. 182).

If we grant that scientific knowledge is neither complete nor unrevisable, then we should prefer to adjust our theories to demonstrable facts, and not write off the facts because they violate our preconcep- 
tions. We may have to make major revisions in our conceptions of scientific tools and methods, but this should not curtail our inquiry.

Alternatively, philosophers of science and philosophical scientists might come to accept such phenomena by conferring labels upon them, such as ESP and NDE, that give us feelings of comprehensibility without any real explanatory power. This is common in science, as noted by Michael Scriven (1976, pp. 188-189):

Physics itself has come to accept the existence of inexplicable events ... There comes a point at which sufficiently elaborate description, documented and worked with for years, gives us the feeling that we have an understanding of the phenomenon thus described. We have not reduced it to another phenomenon, but this only offends our sense of aesthetics, not our scientific sense.

It should be noted, however, that this is a legitimate part of the scientific process and the culmination of years of research, and not the dismissal of ignorant disinterest. This approach would admit that there are genuine limits to our abilities to explain one phenomenon in terms of other phenomena. But it would still advocate the study of these phenomena and the variables that facilitate or frustrate their study. If it is plausible to consider such phenomena as ESP, psychosomatics, and NDEs as objects of scientific study, as I would urge, then our conceptions of the tools and limits of scientific precision need to be broadened in at least two areas, on the objectivity and knowability of the universe.

If thesis $\mathrm{A}$ at the beginning of this paper prove true, then we may need to modify substantially our ideas concerning the objectivity of the natural world that science studies. If it prove the case that the fall of dice, the conditions of living organisms, and the impressions of one's brain are all affected by mental convictions, even at a distance and without intervening physical mechanisms, then we should also ask to what extent such mental influences affect other physical phenomena, from Brownian or bacterial movement, to weather patterns after rain dances, to the uncanny successes of archeological expeditions. We may find that, in fact, most of modern science, its methods and experiments, is relatively free of interference from the sheep-goat effect, just as Heisenberg's principles need trouble us little in the realm of macrolevel physical interactions.

If in fact we find that some experiments are affected by sheep-goat interactions, then we shall want to explore the nature of the variables that render them vulnerable to such mental influences more than 
other less-influenced experiments. This process of looking for important variables, however, will be one of much more subjective psychological types of analyses, difficult to quantify and catalog, which had previously been thought irrelevant to much of natural science.

Thus the admission of the possible influence of mental states on scientific experiments places both theoretical limits and practical problems on the tools of what we tend to think of as "exact science." We end up with situations in which the objects of our investigations cannot even theoretically be separated from consideration of the mindframes of their human investigators.

But the problems of determining (a) what the mindframes of those human investigators are, (b) how those mindframes affect the actual physical interactions of the objects being studied, and (c) which types of experiments seem particularly prone to or immune from influence of the sheep-goat effect, and measuring the variables therein-all of these constitute issues that most scientists heretofore have been only too content to pronounce irrelevant. If these problems become important, natural science will become far more complicated and less precise than it has seemed hitherto.

On the other hand, if thesis $B$ at the beginning of this paper prove true, and there indeed exist other dimensions in which other energies or forms of life may exist, to which humans have at best inferential and occasional altered-state mental access, then again notions of the objectivity of experience are challenged, from a slightly different perspective. To accommodate such problems partially, we might change our definition of intersubjectivity from referring to "perceivable by several subjects at the same time in the same place," to "perceived by all subjects in the same condition and the same mental states."

Still at the same time we would want to build in provisions for distinguishing between physicochemically explicable perceptions, such as of a buzzing in one's ears, and perceptions that are not even conceivably explicable on a physicochemical model, such as of past or future events. Once again, if thesis B be true, and scientists were to concede that studies of experiences of other dimensions were legitimate, we should face such questions as:

What meditative, near-death, or drug-induced states enable humans to have experiences that are intersubjective at least in the sense that others have similar experiences while in similar states? To what extent do such experiences depend on the structure of the universe? If certain experiences contain elements that could best, or only, be explained on the theory of other-dimensional interactions, what might the nature or geography of those other dimensions be? 
This might be a bit like sending spelunkers into passages too tiny for more than one person to breathe at a time, and compiling their accounts to come to rough conclusions about a cave we may never experience ourselves. If these ever become valid questions for science, as proponents of this psychic dimension theory believe they will, then this too would open our understanding of our world to a range of psychological variables that must be studied largely through the unsophisticated tools of the soft or social sciences. In other words, if we have to collect individuals' subjective accounts of their experiences of other dimensions in order to come to an understanding of either death or dimensionality or consciousness, then the problems of language, mindset, and data interpretation loom immense, in a way that the natural sciences presently and prudently eschew.

Even through such approaches, however, the mechanisms by which consciousness interacts with bodies, or by which altered states of consciousness might enable access to intersubjective experiences of other realms in more than a metaphoric sense, remain a mystery.

This paper is not meant as an indictment of modern science in any sense. Science has undergone many paradigm shifts both in method and in what were thought appropriate objects of study. It has come to accommodate many phenomena that seemed anomalous to scientists of earlier eras. Surely it will continue to progress in such ways. Rather, it is the point of this paper that (a) if such anomalies in fact exist, radically new paradigms of science may be necessary to accommodate them; and (b) the variables involved in accommodating such fields to the scientific method may open up realms of uncertainty, subjectivity, or even unknowability, that present day science has not yet fully explored.

\section{References}

Back, A. and Kim, D. (1979). Towards a Western philosophy of the martial arts. Journal of the Philosophy of Sport, 6, 22.

Baird, A.T. (Ed.). (1944). One hundred cases for survival after death. New York, NY: Bernard Ackerman.

Becker, C. (1979). Concepts and roles of God in Tenrikyo. Tenri Journal of Religion, 13, 1-28.

Benson, H. (1971). Physical aspects of psi. In Angoff, A., and Shapin, B. (Eds.), A century

- of psychical research: The continuing doubts and affirmations. New York, NY: Parapsychology Foundation.

Binkley, R. (1966). Philosophy and the survival hypothesis. Journal of the American Society for Psychical Research, 60, 27-31.

Bruner, J., and Postman, L. (1958). On the perception of incongruity: A paradigm. In 
Beardsley, D.C., and Wertheimer, M. (Eds.), Readings in perception. New York, NY: Van Nostrand.

Burt, C. (1967). Psychology and parapsychology. In Smythies, J.R. (Ed.), Science and $E S P$. London, England: Routledge and Kegan Paul.

Delacour, J.-B. (1973). Glimpses of the beyond (Trans. by Garside, E.B.). New York, NY: Delacorte.

Farrer, A. (1965). Saving belief. New York, NY: Morehouse-Barlow.

Geach, P. (1977). Providence and evil. Cambridge, England: Cambridge Universtiy Press.

Hart, H. (1953). The psychic fifth dimension. Journal of the American Society for Psychical Research, 47, 7.

Hick, J. (1976). Death and eternal life. New York, NY: Harper and Row.

Hick, J. (1977). Eschatological verification reconsidered. Religious Studies, 12, 191-193.

Jacobson, N. (1974). Life without death? (Trans. by La Farge, S.). New York, NY: Delacorte.

Johnston, R.W. (1976). Dangerous delusion. Sports Illustrated, October 18, pp. 88-92 + passim.

Kuhn, T. (1970). The structure of scientific revolutions (2nd ed.). Chicago, IL: University of Chicago Press.

Miller, D.E. (1980). A state of grace. Atlantic Monthly, September, pp. 83-88.

Osis, K., and Haraldsson, E. (1977). At the hour of death. New York, NY: Avon.

Palmer, J. (1973). ESP scoring as predicted from four definitions of the sheep-goat variable. Pp. 37-39 in Roll, W.R., Morris, R.L., and Morris, J.D. (Eds.), Research in parapsychology, 1972. Metuchen, NJ: Scarecrow Press.

Palmer, J. (1975). Influence of psychological set on ESP and OBEs. Journal of the American Society for Psychical Research, 69, 193-212.

Pratt, J.C. (1979). Parapsychology, normal science, and paradigm change. Journal of the American Society for Psychical Research, 73, 17-28.

Pribram, K. (1979). Holographic memory. Psychology Today, February, pp. 70-72 + passim.

Ring, K. (1980). Life at death: A scientific investigation of the near-death experience. New York, NY: Coward, McCann and Geoghegan.

Schmeidler, G. (1963). Predicting good and bad scores in a clairvoyance experiment. Journal of the American Society for Psychical Research, 37, 210-221.

Scriven, M. (1976). Explanations of the supernatural. In Thakur, S.C. (Ed.), Philosophy and psychical research. London, England: George Allen and Unwin.

Tart, C.T. (1972). States of consciousness and state-specific sciences. Science, 176, 1203-1210.

Tart, C.T. (1979). Emergent interactionism and consciousness. In Shapin, B., and Coly, L. (Eds.), Brain/mind and parapsychology. New York, NY: Parapsychology Foundation. 